\title{
Mapping the Climate Suitability Using MaxEnt Modeling Approach for Ceylon Spinach (Basella alba L.) Cultivation in India
}

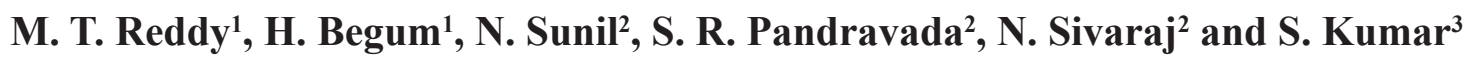 \\ Received : 09 th November, 2014 / Accepted : $16^{\text {th }}$ March, 2015
}

\begin{abstract}
Ceylon spinach (Basella alba L.) is a traditional leafy vegetable of multiple virtues largely underutilized and underexploited in India. Currently, it is of increasing value and utilization necessitating extending its cultivation for increased production by identifying potential areas through crop modeling. Mapping the potential pockets is an iterative process and this study is the first attempt to model state-wise climate suitability for Ceylon spinach cultivation in India. Geographical information on the current cultivation sites of Ceylon spinach together with bioclimatic variables, the maximum entropy (MaxEnt) model were used to analyze and predict its distribution and to develop preliminary habitat suitability map for Ceylon spinach in India. The results show that the MaxEnt model can be used to study the climatic suitability for Ceylon spinach cultivation. The most suitable area identified in this study is slightly southward which includes parts of Tamilnadu, Pondicherry, Maharashtra, Orissa, West Bengal, Bihar, Madhya Pradesh, Uttar Pradesh, Rajasthan and Gujarat. The MaxEnt model performed better than random with an average training and test AUC values of 0.953 and 0.994 , respectively. The constructed model had excellent goodness-of-fit and excellent predictive accuracy and therefore it is suitable and/or applicable for predicting the geographic distribution of Ceylon spinach cultivation in India.
\end{abstract}

Keywords: AUC, Climate suitability, DIVA-GIS, Goodness-of-fit, MaxEnt model, Model accuracy, ROC curve

\section{INTRODUCTION}

Ceylon spinach (Basella alba L., 2n=48.) belongs to the family Basellaceae. It is also known as Indian spinach, Malabar spinach, and vine spinach. It is native to tropical Asia (Grubben and Denton, 2004) and thrives well in tropical and subtropical climates (Grubben, 1997). It is one of the important underutilized and underexploited tropical leaf vegetables widely adapted to a variety of soils and climates (Reddy et al., 2014). Tender shoots with succulent stem along with thick, semi-succulent and mucilaginous leaves are used as leafy vegetable (Reddy et al., 2014). It is rich in food value with the presence of minerals, vitamins, proteins, carbohydrates and dietary fibre (Adeboye, 1996). It is extremely heat tolerant (Grubben and Denton, 2004), frost tender (Reddy et al., 2014) and short-day plant (Reddy et al., 2014).

It is a fast growing herbaceous perennial with twining or creeping habit (Reddy et al., 2014). It has significant economic, nutritional and medicinal value and plays a vital role in food, nutritional and economic security (Maundu et al., 1999; Reddy et al., 2014).

The landraces of Ceylon spinach are under cultivation in tribal, rural and peri-urban vegetable farming systems by the tribal folks, small and marginal farmers of south India (Reddy et al., 2014). As leafy vegetables including Ceylon spinach are increasingly utilized in Indian vegetarian diet, it is essential to increase its production to meet the growing demand. Its production can be enhanced either by improving the productivity of the cultivars or by bringing new potential areas under its

1 Vegetable Research Station, Dr. Y. S. R. Horticultural University, Rajendranagar, Hyderabad-500 030, Telangana, India

2 National Bureau of Plant Genetic Resources, Regional Station, Rajendranagar, Hyderabad-500 030, Telangana, India

College of Horticulture, Dr. Y. S. R. Horticultural University, Rajendranagar, Hyderabad-500 030, Telangana, India 
cultivation. For any crop, its cultivation depends on interactions between thermal and water resources with the climate plyaing an important factor. Climate suitability maps are useful to determine potential areas which will have the greatest success for growing a new crop. The basis for the present study is the general notion that knowledge about environmental conditions at locations where particular plant species are successfully grown should provide a basis for summarizing crop growth parameters throughout the region. It is pertinent to have a model that provides a plausible prediction of the area that is suitable for Ceylon spinach cultivation.

Currently, ecological niche models (ENMs) and species distribution models (SDMs) are increasingly being used to map potential distributions of many species. ENMs and SDMs integrate species occurrence data with climatic and other environmental variables and generate realized distribution maps of species (Bentlage et al., 2013) that are used to design scientific surveys, plan and manage sustainable farming systems. Generally SDMs are used for modeling animal and plant distributions in natural environments, but have rarely been used to develop landscape models for cultivated crops (Evans et al., 2010). Even though, many models like BIOCLIM, BLOMAPPER, DIVA, DOMAIN, CLIMEX, GAM, GLM, GARP and Maximum entropy (MaxEnt) have been used in species distribution modeling (Kriticos and Randall, 2001; Phillips et al., 2004; Guisan and Thuiller, 2005; Elith et al., 2006; Sun and Liu, 2010), MaxEnt unravels the best predictive capacity and was the most precise (Moffett et al., 2007; Wang et al., 2007; Giovanelli et al., 2008; Saatchi et al., 2008; Wu and Li, 2009; Kumar et al., 2014) giving the most accurate distribution function based on best entropy (Kumar et al., 2014). Several studies indicated that MaxEnt modeling performed well or better than the other models (Elith et al., 2006; Hernandez et al., 2006; Phillips et al., 2006). MaxEnt is 'the least biased estimate possible on the given information; i.e., it is maximally non-committal with regard to missing information' (Jaynes, 1957) and estimates the probability of presence of a species based on occurrence records and randomly generated background points by finding the maximum entropy distribution (Phillips et al., 2006). The evaluation of model accuracy is an essential step as it indicates the level of accuracy of the estimations. The concept of model validation (Bair, 1994; Oreskes, 1998) is generally accepted and interpreted in terms of suitability for a particular purpose (Rykiel Jr, 1996; Sargent, 2001). Several methodologies have been used for model accuracy assessment in species distribution modeling. The receiver operating characteristic (ROC) and defined thresholds are important methodologies used for the evaluation of MaxEnt model quality.

In view of the above, an attempt has been made using MaxEnt with presence-only modeling algorithm with an objective to provide a climate suitability map for Ceylon spinach cultivation, based on regional crop presence data at the county level for India.

\section{MATERIALS AND METHODS}

\section{Crop species occurrence data}

Majority of the species distribution models including MaxEnt use precise geographic coordinates (latitude/ longitude) of species occurrences. Precise geographical coordinates recorded using a Global Positioning System (Garmin GPS-12) during an eco-geographic survey conducted by the National Bureau of Plant Genetic Resources, Regional Station, Hyderabad in collaboration with Vegetable Research Station, Dr. Y. S. R. Horticultural University, Rajendranagar during 2010 was used. Following random sampling strategy, crop presence data of Ceylon spinach was collected from five points covering two districts of Andhra Pradesh and one of Odisha, India (Table $01)$. Therefore, a total of 5 reference points $(n=5$ 
records) were used to generate a preliminary climate suitability map of Ceylon spinach, thus making use of the best available data. Of the total sample records $(n=5), 60 \%$ was selected for training data; the other portion $(40 \%)$ was used for test data for both MaxEnt analysis and evaluation of MaxEnt model.

\section{Climate data}

We obtained climate data for 19 bioclimatic layers from the WorldClim dataset (Hijmans et al., 2005; http://www.worldclim.org/) at $1 \mathrm{~km}$ spatial resolution to represent current climatic conditions. The WorldClim dataset was generated using an interpolation technique using altitude and monthly temperature and precipitation records from 1950 to 2000, which represents long term (1950-2000) monthly means of maximum, minimum and mean temperatures and total rainfall. The 19 bioclimatic variables that define general trends, seasonality and extremes are considered biologically more meaningful than simple monthly or annual averages of temperature and precipitation in defining a species' ecophysiological tolerances (Nix, 1986; Kumar et al., 2009).

\section{Modeling procedure}

MaxEnt algorithm version 3.3.3k (Phillips et al., 2006) was used for mapping the potential geographic distribution of Ceylon spinach in the world in general and in India in particular using 5 geo-reference points (Table 01) along with WorldClim dataset. Default settings were used in MaxEnt so that the complexity of the model varied depending upon the number of data points used for model fitting. The ASCI file generated by the MaxEnt run for Ceylon spinach occurrence points was imported to grid file using DIVA-GIS software version 7.5 (Hijmans et al., 2012). The grid layer generated for each run was overlaid on India shape file using DIVA-GIS and analysed (Sundar and Mitsuko, 2005). The output from MaxEnt is an estimate of habitat suitability for a species that generally varies from 0 (lowest) to 1 (highest). Classification of climatic zones in terms of their suitability for Ceylon spinach cultivation was arrived at by determining the existence probability using this model.

\section{Statistical analysis of MaxEnt model}

The relevance, goodness-of-fit, predictive accuracy of the MaxEnt model was tested in two ways: 1) through receiver operating characteristic (ROC) plots, and 2) through defined thresholds.

Table 01: Occurrence points of Ceylon spinach used for MaxEnt analysis

\begin{tabular}{cccc} 
& & \multicolumn{2}{c}{ Geographic coordinates } \\
S. No. & Crop species & Latitude & Longitude \\
& & $\left({ }^{\circ} \mathrm{N}\right)$ & $\left({ }^{\circ} \mathrm{E}\right)$ \\
\hline 1 & Basella alba $\mathrm{L}$. & 18.76913 & 84.40862 \\
2 & Basella alba $\mathrm{L}$. & 18.35955 & 83.87347 \\
3 & Basella alba $\mathrm{L}$. & 18.31328 & 83.57062 \\
4 & Basella alba $\mathrm{L}$. & 18.58172 & 82.91382 \\
5 & Basella alba $\mathrm{L}$. & 18.62643 & 82.58880 \\
\hline
\end{tabular}




\section{RESULTS AND DISCUSSION}

The distribution of Ceylon spinach cultivation depends on climate, socio-economic conditions, local production technologies, soil type, geographic characteristics, crop varieties, human activity, and so on. In this study, the environmental conditions at the current locations of Ceylon spinach crop in south India were utilized to to predict the probability of suitable conditions existing for the same crop at other locations of the globe and/or country using MaxEnt model.

\section{Analysis of global climate suitability map of Ceylon spinach generated using MaxEnt model}

The global climate suitability for Ceylon spinach cultivation using MaxEnt model is depicted in Figure 01. Warmer colors show areas where better predicted conditions exist. White dots show the presence locations used for training, while violet dots show test locations. The red color indicates areas with a high probability of occurrence, the blue and green represent moderate probability, the yellow color represents low probability of occurrence and the white indicates areas not suitable for Ceylon spinach. In fact, this worldwide climate suitability map can be used in the countries that lack precise coordinates of Ceylon spinach occurrences and generate a preliminary climate suitability map of Ceylon spinach because it may be too late to wait for the precise coordinates of Ceylon spinach occurrences to generate a perfect climate suitability map.

\section{Analysis of state-wise Indian national level climate suitability map of Ceylon spinach generated using MaxEnt model and DIVA- GIS}

State-wise Indian national level climate suitability map for Ceylon spinach was generated using MaxEnt software and DIVAGIS (Figure 02). Climatic zones were classified in terms of their suitability for cultivation, based on the existence probability, determined through MaxEnt. The geographical ranges of the excellent area (0.7087-1.0000), optimum area $(0.5315-0.7087)$, suitable area $(0.3543$ $0.5315)$, less suitable area (0.1772-0.3543) and unsuitable area (0.0000-0.1772) are shown in the climate suitability map with different colours (Figure 02). The image uses colours to indicate predicted probability, with the red indicating probability (0.71 to 1.0$)$ of high suitability, green indicating conditions of suitability and lighter shades of green indicating low suitability conditions. The suitable pockets in this study lie slightly in the central and southward which includes parts of Tamil Nadu, Pondicherry, Maharashtra, Orissa, West Bengal, Bihar, Madhya Pradesh, Uttar Pradesh, Rajasthan and Gujarat. These states had the potential regions for introducing and cultivating the Ceylon spinach landraces and for planning in-situ on-farm conservation sites in the light of climate change scenario. In addition, most of the western region has less suitable area; and the northern parts of India had 'unsuitable' to a 'less suitable' or 'suitable' area.

The preliminary state-wise Indian national level climate suitability map thus developed in this study (Figure 02) can be refined to district scale by integrating detailed species occurrence data and higher resolution predictor variables. This climate suitability map will be useful to agriculture managers and policymakers for designing local, regional and national-level planning for Ceylon spinach-based farming systems in India.

\section{Evaluation of quality of MaxEnt model}

Model utility is dependent on an evaluation of performance. This is a critical element of modelbuilding. As with any modeling approach, the fit or accuracy of the model should be tested to determine the relevance of the model. The utility of MaxEnt in real world applications requires the knowledge of the model's accuracy. 


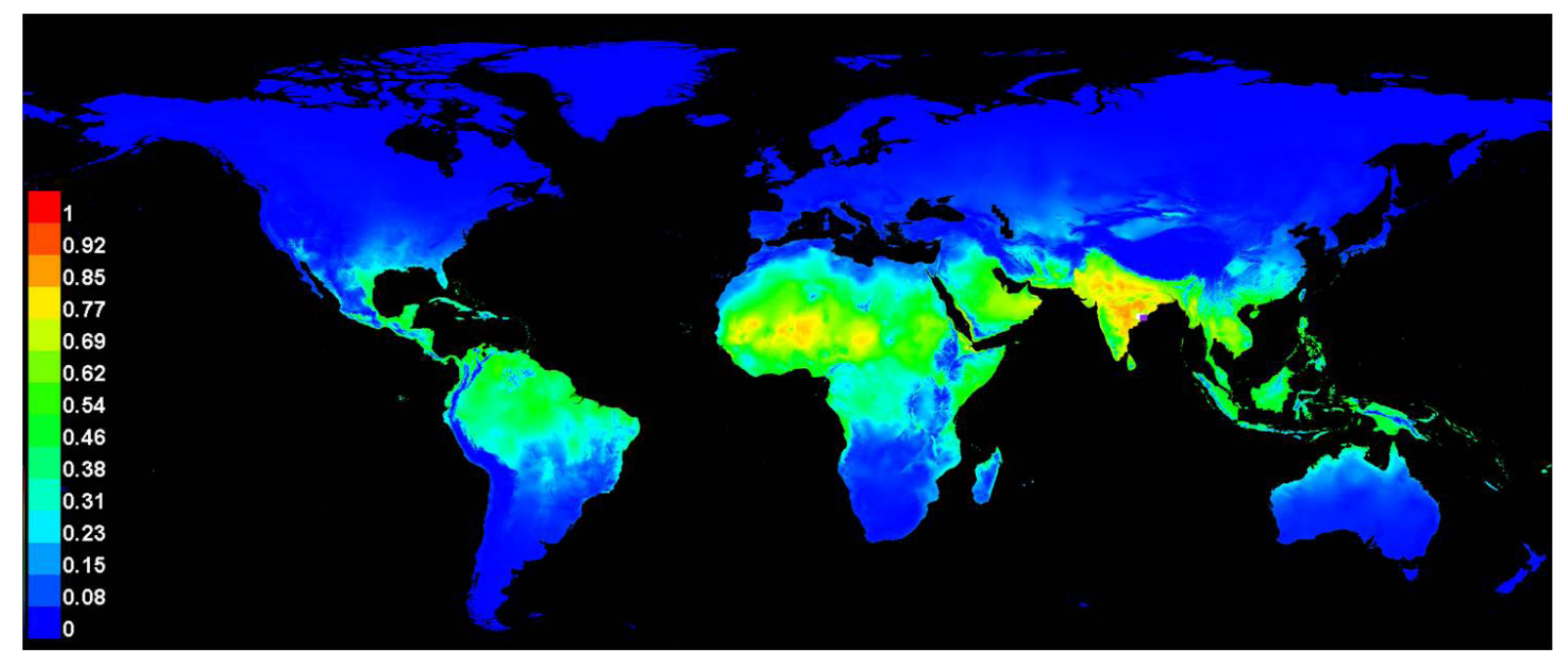

Figure 01: Worldwide cultivation potential of Ceylon spinach based on MaxEnt model

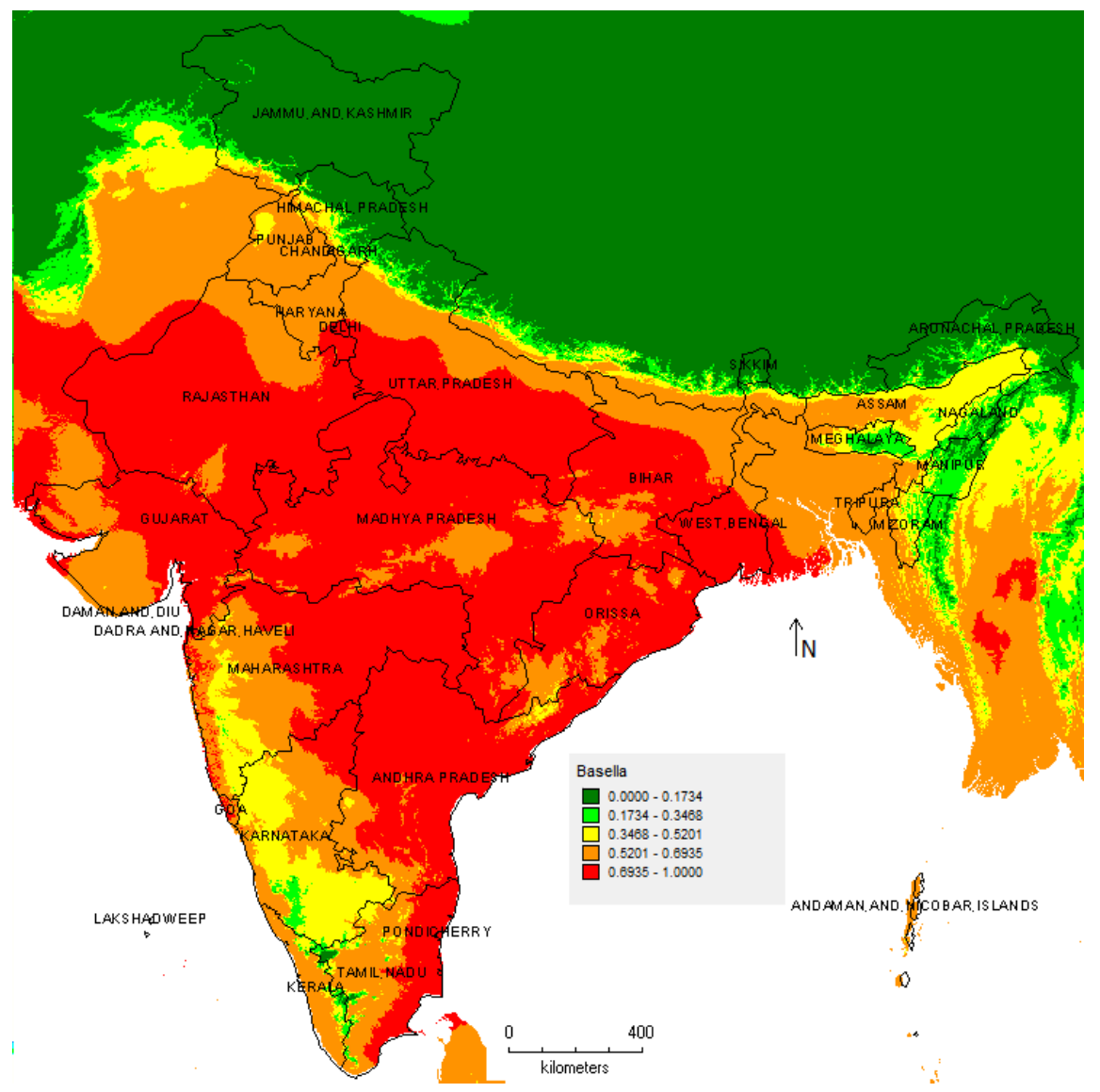

Figure 02: Climate suitability map for Ceylon spinach cultivation in India derived using MaxEnt software and DIVA-GIS 


\section{Receiver operating characteristic curve}

The first approach used for MaxEnt model evaluation in this study was the ROC. A ROC plot is a plot of sensitivity and 1-specificity, with sensitivity representing how well the data correctly predicts presence, whereas specificity provides a measure of correctly predicted absences (Fielding and Bell, 1997). The ROC curve is generally used to evaluate the simulation accuracy of the model (Hanley and McNeil, 1982). The area below the ROC curve, i.e. the value of the area under the curve (AUC) indicates the predictive accuracy of the model. The AUC is a ranked approach for assessing model fit that determines the probability that a presence location will be ranked higher than a random background location (Phillips et al., 2006). AUC's are developed from ROC plots for assessing differences in species suitability for developed models compared to a random distribution. A binomial test of omission (known areas of presence/ predicted absence) can then be used to test whether or not this difference is significant (Philips et al., 2006).

The '40' entered for 'random test percentage'; command the program to randomly set aside $40 \%$ of the sample (presence) records for testing. This allows the program to do some simple statistical analysis. Much of the analysis uses a threshold to make a binary prediction with suitable conditions predicted above the threshold and unsuitable below. The picture (Figure 03) shows the omission rate and predicted area as a function of the cumulative threshold. The omission rate was calculated both on the training records and on the test records (60\% and $40 \%$ of the presence records, respectively). The omission rate should be close to the predicted omission, because of the definition of the cumulative threshold. Figure 3 shows how testing and training omission and predicted area vary with the choice of cumulative threshold. The omission on test samples (sky blue line) is a very good match to the predicted omission rate (black line), the omission rate for test data drawn from the MaxEnt distribution itself. The predicted omission rate is a straight line (black line), by definition of the cumulative output format. In some situations, the test omission line (sky blue line) lies well below the predicted omission line (black line), while in some other situations the test omission line (sky blue line) lies well above the predicted omission line (black line). A common reason is that the test and training data are not independent, for example if they derive from the same spatially auto-correlated presence data. This indicates that MaxEnt model was significantly better than random in binomial test of omission and predicted area curve. Since only occurrence data is available and no absence data, 'fractional predicted area' (the fraction of the total study area predicted present) is used instead of more standard commission rate (fraction of absences predicted present).

The next plot is the ROC curve for the same data (Figure 04) and the specificity is defined using predicted area, rather than true commission. This implies that the maximum achievable AUC is less than 1. If test data is drawn from the Maxent distribution itself, then the maximum possible test AUC would be 0.898 rather than 1 and in practice the test AUC may exceed this bound. The significance of the (ROC) curve is also quantified by the AUC which has values that typically range from $0.5-1.0$, indicating the following degrees of predictive accuracy (Swets, 1988): 0.50-0.60 (fail), 0.60-0.70 (poor), 0.70-0.80 (fair), 0.80-0.90 (good), and 0.90-1.0 (excellent). Values close to 0.5 indicate a fit no better than that expected by random, while a value of 1.0 indicates a perfect fit. It is possible to have values less than 0.5 which indicates that a model fits worse than random (Engler et al., 2004). In general, the higher the AUC value, the more accurate the prediction of the constructed model (Elith, 2002) and when the AUC values are more than 0.75, the constructed model is applicable. In the present study, the AUC of the constructed model based on the potential climatic factors affecting the 
distribution of the Ceylon spinach cultivation zone was 0.953 and 0.994 , for training and test data, respectively. This AUC value indicated that the constructed model is applicable and had 'excellent' predictive accuracy and therefore it was suitable for predicting the geographic distribution of Ceylon spinach cultivation in India. The course-scale MaxEnt modeling predicted the suitable areas in the Model (Figure 04) with excellent goodness-of-fit ( $\mathrm{AUC}=0.953$ for training data and 0.994 for test data).

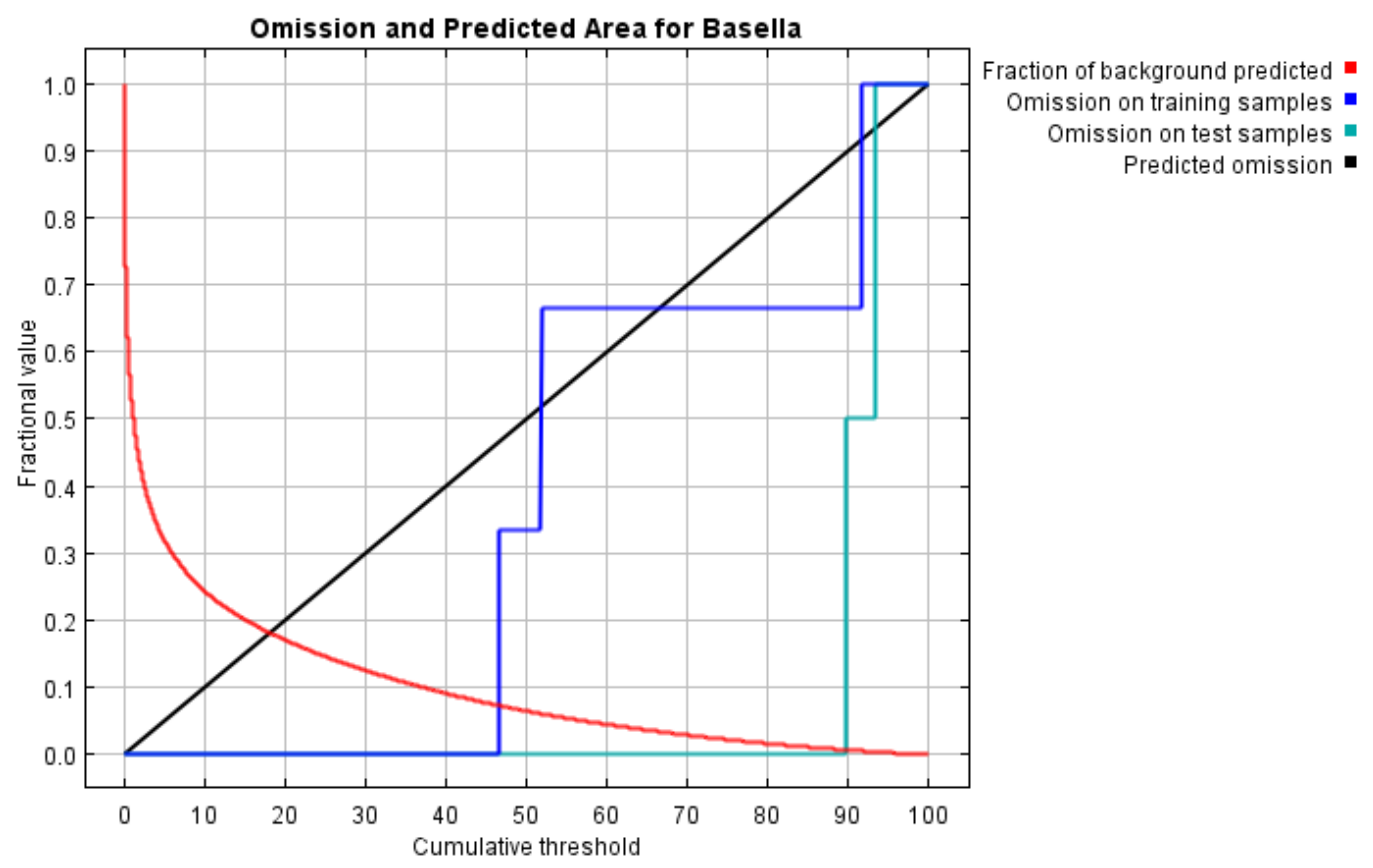

Figure 03: Graph generated by MaxEnt software showing omission and predicted area for Ceylon spinach

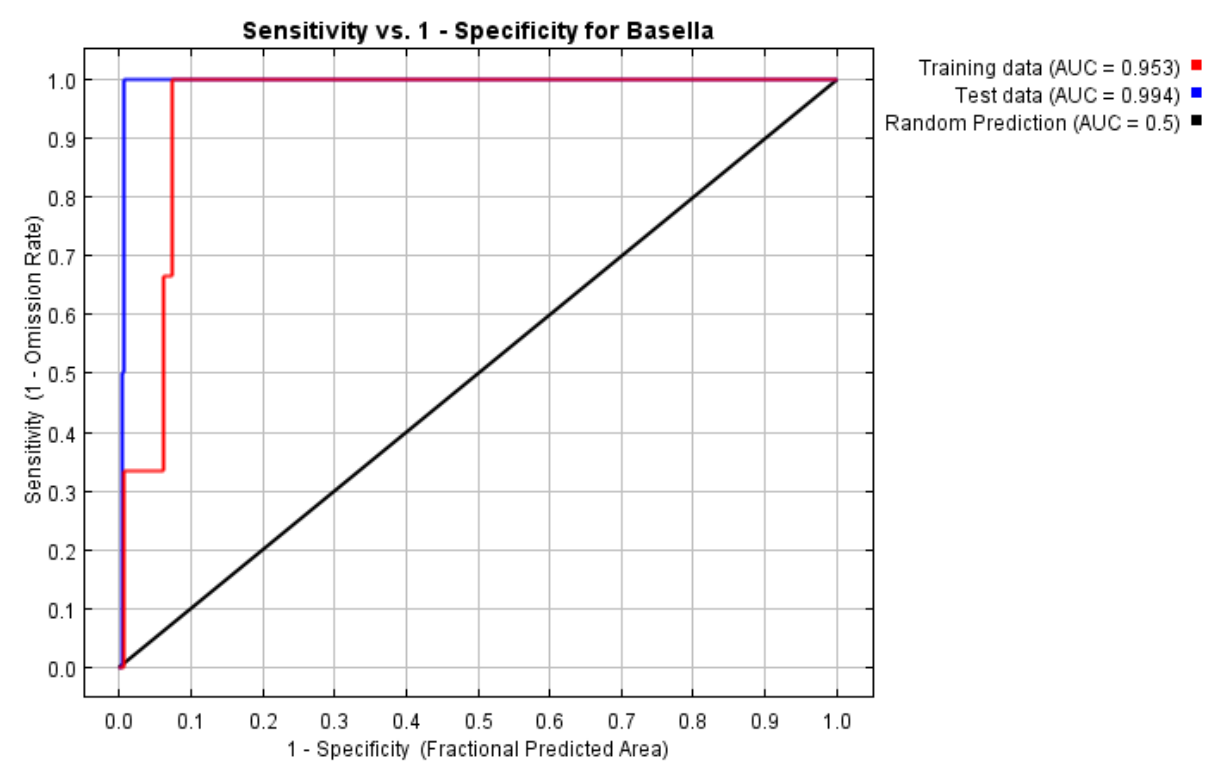

Figure 04: ROC curve of sensitivity versus specificity for Ceylon spinach 


\section{Defined thresholds}

The second approach used for MaxEnt model evaluation in this study was the defined thresholds. This approach involves selecting thresholds to establish sites that are considered suitable or unsuitable for the species of interest. Once a threshold has been identified, locations can be classified as suitable or unsuitable for the species of interest. These thresholds are established by maximizing sensitivity while minimizing specificity (Fielding and Bell, 1997; Phillips et al., 2006). Threshold values differ for each model and are selected to provide a desired balance between omission and commission (Fielding and Bell, 1997; Hernandez et al., 2006). Where this threshold is applied is determined from ROC plots and is selected at the discretion of the modeller. For example, when dealing with endangered species, the modeller may want to maintain zero omission error, while identifying the minimum predicted area. However, if the modeller is interested in identifying any possible area that a species might use, then they would want to minimize commission error (Pearson et al., 2007).

In this study, some common thresholds and corresponding omission rates for the evaluation of MaxEnt model accuracy are as follows (Table 02). Since test data are available and the number of test samples is less than 25 , binomial probabilities are calculated using a normal approximation to the binomial. These are 1-sided $p$-values for the null hypothesis that test points are predicted no better than by a random prediction with the same fractional predicted area. The 'Balance' threshold minimizes $6.00^{*}$ training omission rate $+0.04^{*}$ cumulative threshold $+1.60^{*}$ fractional predicted area.

Table 02: Common thresholds and corresponding omission rates for the threshold- dependent binomial tests of omission

\begin{tabular}{|c|c|c|c|c|c|c|}
\hline $\begin{array}{l}\text { Cumulative } \\
\text { threshold }\end{array}$ & $\begin{array}{l}\text { Logistic } \\
\text { threshold }\end{array}$ & Description & $\begin{array}{l}\text { Fractional } \\
\text { predicted area }\end{array}$ & $\begin{array}{l}\text { Training } \\
\text { omission rate }\end{array}$ & $\begin{array}{c}\text { Test } \\
\text { omission rate }\end{array}$ & P-value \\
\hline 1.000 & 0.023 & Fixed cumulative value 1 & 0.511 & 0.000 & 0.000 & $2.61 \mathrm{E}-1$ \\
\hline 5.000 & 0.111 & Fixed cumulative value 5 & 0.318 & 0.000 & 0.000 & $1.012 \mathrm{E}-1$ \\
\hline 10.000 & 0.205 & Fixed cumulative value 10 & 0.243 & 0.000 & 0.000 & $5.901 \mathrm{E}-2$ \\
\hline 46.566 & 0.521 & Minimum training presence & 0.073 & 0.000 & 0.000 & $5.37 \mathrm{E}-3$ \\
\hline 46.566 & 0.521 & $\begin{array}{l}10 \text { percentile training } \\
\text { presence }\end{array}$ & 0.073 & 0.000 & 0.000 & $5.37 \mathrm{E}-3$ \\
\hline 46.566 & 0.521 & $\begin{array}{l}\text { Equal training sensitivity } \\
\text { and specificity }\end{array}$ & 0.073 & 0.000 & 0.000 & $5.37 \mathrm{E}-3$ \\
\hline 46.566 & 0.521 & $\begin{array}{l}\text { Maximum training } \\
\text { sensitivity plus specificity }\end{array}$ & 0.073 & 0.000 & 0.000 & $5.37 \mathrm{E}-3$ \\
\hline 89.767 & 0.766 & $\begin{array}{l}\text { Equal test sensitivity and } \\
\text { specificity }\end{array}$ & 0.007 & 0.667 & 0.000 & $5.181 \mathrm{E}-5$ \\
\hline 89.767 & 0.766 & $\begin{array}{l}\text { Maximum test sensitivity } \\
\text { plus specificity }\end{array}$ & 0.007 & 0.667 & 0.000 & $5.181 \mathrm{E}-5$ \\
\hline 4.488 & 0.098 & $\begin{array}{l}\text { Balance training omission, } \\
\text { predicted area and } \\
\text { threshold value }\end{array}$ & 0.330 & 0.000 & 0.000 & $1.09 \mathrm{E}-1$ \\
\hline 7.634 & 0.159 & $\begin{array}{l}\text { Equate entropy of } \\
\text { thresholded and original } \\
\text { distributions }\end{array}$ & 0.272 & 0.000 & 0.000 & $7.421 \mathrm{E}-2$ \\
\hline
\end{tabular}




\section{CONCLUSIONS}

A climate suitability modeling was attempted for an under-utililzed and underexploited tropical leafy vegetable species, Ceylon spinach, based on SDM: MaxEnt. The present study would be the first of its kind in India using MaxEnt for assessing climate suitability for Ceylon spinach. Results provide insight into the different areas of its probable cultivation in India. The study presents a novel approach to assess the potential areas for extending the cultivation of Ceylon spinach using regional-level occurrence data using MaxEnt model. AUC measures derived from training and test data indicate that MaxEnt produced significantly accurate results. The sensitivity versus 1-specificity graph indicated that the MaxEnt model had 'good' predictive accuracy (AUC $=0.953$ for training data and 0.994 for test data) in terms of the relationship between extending the Ceylon spinach cultivation and climate. The results show that the MaxEnt model can be used to study the climatic suitability for Ceylon spinach cultivation. MaxEnt modeling provides a tool for researchers and managers to understand the potential extent of Ceylon spinach species spread in India.

\section{ACKNOWLEDGEMENTS}

The senior author is highly grateful to the National Bureau of Plant Genetic Resources, Regional Station, Hyderabad for sharing the occurrence points of Basella alba L. with the Vegetable Research Station, Dr. Y.S.R. Horticultural University.

\section{REFERENCES}

Adeboye, O.C. (1996). Proximate composition and nutrient analysis of six selected leaf vegetables of South West Nigeria. Ife J. Agric. 18: 56.

Bair, E.S. (1994). Model (in)validation - a view from courtroom. Ground Water, 32: 530-531.

Bentlage, B., Peterson, A.T., Barve, N. and Cartwright, P. (2013). Plumbing the depths: extending ecological niche modeling and species distribution modeling in three dimensions. Glob. Ecol. Biogeogr., 22(8): 952-961.

Elith, J. (2002). Quantitative methods for modeling species habitat: Comparative performance and an application to Australian plants. In: Quantitative Methods for Conservation Biology (Ferson S., Burgman M., Eds.). New York, Springer, pp. 39-58.

Elith, J., Graham, C.H., Anderson, R.P., Dudik, M., Ferrier, S., Guisan, A., Hijmans, R.J., Huettmann, F., Leathwick, R., Lehmann, A., Li, J., Lohmann, L.G., Loiselle, B.A., Manion, G., Moritz, C., Nakamura, M., Nakazawa,Y., Overton, McC, J., Peterson, A.T., Phillips, J., Richardson, K., Scachetti-Pereira, R., Schapire, E., Soberon, J., Williams, S., Wisz, M. and Zimmermann, E. (2006). Novel methods improve prediction of species' distributions from occurrence data. Ecography, 29: 129-151.

Engler, R., Guisan, A. and Rechsteiner, L. (2004). An improved approach for predicting the distribution of rare and endangered species from occurrence and pseudo-absence data. J. Appl. Ecol., 41: 263-274. 
Evans, J.M., Fletcher, Jr R.J. and Alavalapati, J. (2010). Using species distribution models to identify suitable areas for biofuel feedstock production. GCB Bioenergy, doi: 10.1111/j.17571707.2010.01040.x.

Fielding, A.H. and Bell, J.F. (1997). A review of methods for the assessment of prediction errors in conservation presence/absence models. Environ. Conserv., 24: 38-49.

Giovanelli, J.G.R., Haddad, C.F.B. and Alexandrino, J. (2008). Predicting the potential distribution of the alien invasive American bullfrog (Lithobates catesbeianus) in Brazil. Biol. Invasions, 10: 585-590.

Grubben, G.J.H. (1997). Tropical Vegetables and their Genetic Resources. Royal Tropical Institute, Amsterdam, Netherlands, 453pp.

Grubben, G.J.H. and Denton, O.A. (2004). Plant Resources of Tropical Africa 2. Vegetable. PROTA Foundation, Wageningen, Backhuys, Leiden, CTA, Wageningen, 4: 103-111.

Guisan, A. and Thuiller, W. (2005). Predicting species distribution: Offering more than simple habitat models. Ecol. Lett., 8: 993-1009.

Hanley, J.A. and McNeil, B.J. (1982). The meaning and use of the area under a Receiver Operating Characteristic (ROC) curve. Radiology, 143: 29-36.

Hernandez, P.A., Graham, C.H., Master, L.L. and Albert, D.L. (2006). The effect of sample size and species characteristics on performance of different species distribution modeling methods. Ecography, 29: 773-785.

Hijmans, R.J., Cameron, S.E., Parra, J.L., Jones, P.G. and Jarvis, A. (2005). Very high resolution interpolated climate surfaces for global land areas. Int. J. Climatol., 25(15): 1965-1978.

Hijmans, R.J., Guarino, L. and Mathur, P. (2012). DIVA-GIS Version 7.5, Manual. Available at: www.diva-gis.org.

Jaynes, E.T. (1957). Information theory and statistical mechanics. Phys. Rev., 106: 620-630.

Kriticos, D. and Randall, R. (2001). Acomparison of systems to analyse potential weed distributions. In: Weed Risk Assessment (Grove R.H., Panetta F.D., Virtue J.G. Eds.). Australia, CSRIO Publishing, pp. 61-79.

Kumar, S., Graham, J., West, A.M. and Evangelista, P.H. (2014). Using district-level occurrences in MaxEnt for predicting the invasion potential of an exotic insect pest in India. Comput. Electron. Agr., 103: 55-62.

Kumar, S., Spaulding, S.A., Stohlgren, T.J., Hermann, K., Schmidt, T. and Bahls, L. (2009). Potential habitat distribution for the freshwater diatom Didymosphenia geminata in the continental US. Front. Ecol. Environ., 7(8): 415-420.

Maundu, P.M., Ngugi, G.W. and Kabuye, C.H. (1999). Traditional Food plants of Kenya. KENRIK, National museums of Kenya. 270p. 
Moffett, A., Shackelford, N. and Sarkar, S. (2007). Malaria in Africa: Vector species' niche models and relative risk maps. PLoS ONE, 2: e824

Nix, H.A. (1986). A biogeographic analysis of Australian elapid snakes. In: Atlas of Elapid Snakes of Australia. Australian Flora and Fauna Series No. 7. Longmore, R., Ed.). Australian Government Publishing Service, Canberra, pp. 4-15.

Oreskes, N. (1998). Evaluation (not validation) of quantitative models. Environ. Health Persp., 106: $1453-1460$.

Pearson, R.G., Raxworthy, C.J., Nakamura, M. and Peterson, A.T. (2007). Predicting species distributions from small numbers of occurrence records: a test case using cryptic geckos in Madagascar. J. Biogeogr., 34(1): 102-117.

Phillips, S.J., Anderson, R.P., Schapire, R.E. (2006). Maximum entropy modeling of species geographic distributions. Ecol. Model., 190(3-4): 231-259.

Phillips, S.J., Dudik, M. and Schapire, R.E. (2004). A maximum entropy approach to species distribution modeling. In: Proceedings of the Twenty-First International Conference on Machine Learning. Banff, Canada, pp. 655-662.

Reddy, M.T., Begum, H., Sunil, N., Pandravada, S.R., Sivaraj, N. and Kumar, S. (2014). Preliminary characterization and evaluation of landraces of Indian spinach (Basella spp. L.) for agroeconomic and quality traits. Plant Breed. Biotech., 2(1): 48-63.

Rykiel Jr, E.J. (1996). Testing ecological models: the meaning of validation. Ecological Modeling 90: 229-244.

Saatchi, S., Buermann, W., Mori, S. and Ter Steege, H. (2008). Modeling distribution of Amazonian tree species and diversity using remote sensing measurements. Remote Sens. Environ., 112: 2000-2017.

Sargent, R.G. (2001). Verification, validation and accreditation of simulation models. In: Peters, B.A., Smith, J.S., Medeiros, D.J., Rohrer, M.W. (Eds.), Proceedings of the 2001 Winter Simulation Conference, December 10-13, Arlington, VA, USA, 106-114.

Sun, W.T. and Liu, Y.T. (2010). Research progress of risk analysis of biological invasion (in Chinese). Chin. Agr. Sci .Bull., 26: 233-236.

Sundar, S.S. and Mitsuko, C. (2005). A geographical information system for the analysis of biodiversity data. Gis Resource Document [WWW document]. URL http://www.pop.psu. edu/gia-core/pdfs/gis_rd_02-27.pdf

Swets, K.A. (1988). Measuring the accuracy of diagnostic systems. Science, 240: 1285-1293.

Wang, Y.S., Xie, B.Y., Wan, F.H., Xiao, Q.M. and Dai, L.Y. (2007). Potential geographic distribution of Radopholus similis in China. Sci. Agri. Sin., 40: 2502-2506.

Wu, W.H. and Li, M.Y. (2009). Methods for predicting potential habitat of Bursaphelenchus xylophilus based on Ecological Niche Model (in Chinese). For. Invent. Plan., 34: 33-38. 